\title{
Article \\ Arterial Hypertension and Diabetes Mellitus in COVID-19 Patients: What Is Known by Gender Differences?
}

\author{
Tiziana Ciarambino ${ }^{1, *}$, Filippina Ciaburri ${ }^{2}$, Venere Delli Paoli ${ }^{3}$, Giuseppe Caruso ${ }^{2}$, Mauro Giordano 4 \\ and Maria $\mathrm{D}^{\prime}$ Avino $^{2}$ \\ 1 Internal Medicine Department, Hospital of Marcianise, 81037 Caserta, Italy \\ 2 Hypertension Unit, Cardarelli Hospital, 80110 Naples, Italy; filippinalibetta@alice.it (F.C.); \\ giuseppe.caruso@gmail.com (G.C.); dott.mariadavino@gmail.com (M.D.) \\ 3 Internal Medicine Department, Cardarelli Hospital, 80110 Naples, Italy; venere.dellipaoli@gmail.com \\ 4 Internal Medicine Department, University of Campania, 80110 Naples, Italy; mauro.giordano@unicampania.it \\ * Correspondence: tiziana.ciarambino@gmail.com
}

Citation: Ciarambino, T.; Ciaburri, F.; Paoli, V.D.; Caruso, G.; Giordano, M.; D’Avino, M. Arterial Hypertension and Diabetes Mellitus in COVID-19 Patients: What Is Known by Gender Differences? J. Clin. Med. 2021, 10, 3740. https://doi.org/10.3390/ jcm10163740

Academic Editor: Pierpaolo Di Micco

Received: 26 June 2021

Accepted: 19 August 2021

Published: 23 August 2021

Publisher's Note: MDPI stays neutral with regard to jurisdictional claims in published maps and institutional affiliations.

Copyright: (c) 2021 by the authors. Licensee MDPI, Basel, Switzerland. This article is an open access article distributed under the terms and conditions of the Creative Commons Attribution (CC BY) license (https:/ / creativecommons.org/licenses/by/ $4.0 /)$.

\begin{abstract}
Background. Severe acute respiratory syndrome coronavirus-2 (SARS-CoV-2) has infected $>160$ million people around the world. Hypertension (HT), chronic heart disease (CHD), and diabetes mellitus (DM) increase susceptibility to SARS-CoV-2 infection. Aims. We designed this retrospective study to assess the gender differences in hypertensive diabetic SARS-CoV-2 patients. We reported data, by gender differences, on the inflammatory status, on the hospital stays, intensive care unit (ICU) admission, Rx and CT report, and therapy. Methods. We enrolled 1014 patients with confirmed COVID-19 admitted into different Hospitals of Campania from 26 March to 30 June, 2020. All patients were allocated into two groups: diabetic-hypertensive group (DM-HT group) that includes 556 patients affected by diabetes mellitus and arterial hypertension and the non-diabeticnon-hypertensive group (non-DM, non-HT group) comprising 458 patients. The clinical outcomes (i.e., discharges, mortality, length of stay, therapy, and admission to intensive care) were monitored up to June 30, 2020. Results. We described, in the DM-HT group, higher proportion of cardiopathy ischemic (CHD) $(47.5 \%$ vs. $14.8 \%$, respectively; $p<0.0001)$ and lung diseases in females compared to male subjects $(34.8 \%$ vs. $18.5 \%$, respectively; $p<0.0001)$. In male subjects, we observed higher proportion of kidney diseases (CKD) (11\% vs. $0.01 \%$, respectively; $p<0.0001)$, a higher hospital stay compared to female subjects (22 days vs. 17 days, respectively, $p<0.0001$ ), a higher admission in ICU $(66.9 \%$ vs. $12.8 \%$, respectively, $p<0.0001)$, and higher death rate $(17.3 \%$ vs. $10.7 \%$, respectively, $p<0.0001)$. Conclusion. These data confirm that male subjects, compared to female subjects, have a higher hospital stay, a higher admission to ICU, and higher death rate.
\end{abstract}

Keywords: COVID-19 infection; diabetes mellitus; arterial hypertension; SARS-CoV-2; outcome; comorbidity

\section{Introduction}

Coronavirus disease 2019 (COVID-19) has infected over 160 million people around the world [1]. Hypertension (HT), chronic heart disease (CHD), and diabetes mellitus (DM), particularly in elderly people, increase susceptibility to severe COVID-19 [2]. In particular, about $12.8 \%$ to $31.2 \%$ of patients with COVID-19 had pre-existing hypertension as far as anamnestic chronic cardio-cerebrovascular disease (16.4\%) and diabetes $(9.7 \%)[3,4]$. Because these patients seem to develop severe forms of COVID-19, an increased rate of mortality in this clinical setting has also been reported [5]. Several studies, in fact, described an increased risk of death in patients with DM and HT [6,7], and from a clinical point of view, inpatients with COVID-19 and comorbidities such as DM and HT, appear to have needed greater intensity of care $[7,8]$. Yet, not univocal data are present, concerning gender differences in inpatients with COVID-19 with DM and HT as comorbidities. A recent metanalysis [9] reported that males affected by COVID-19 are more likely to develop 
adverse symptoms or prognosis [9]; therefore, the authors suggest gender as a risk factor for prognosis of COVID-19 [9].

In this report, we designed a retrospective observational study to assess the gender differences in DM-HT SARS-CoV-2 inpatients in an Italian cohort of subjects observed in different Hospitals as dedicated units for COVID-19 in Southern Italy. We reported data on gender differences for clinical presentation and evolution (e.g., duration of hospitalization and/or admission in an intensive care unit (ICU) and/or discharge and/or therapeutic regimens) regarding inflammation (e.g., levels of $\mathrm{C}$-reactive protein).

\section{Methods}

We enrolled 1014 patients with confirmed COVID-19 admitted into different Hospitals of Campania (different Campania Hospital as dedicated Intensive care unit (ICU) for COVID-19) from 26 March to 30 June, 2020. All patients were allocated into two groups: diabetic-hypertensive group (DM-HT group), which includes 556 patients affected by diabetes mellitus and arterial hypertension, and the nondiabetic-non-hypertensive group (non-DM, non-HT group), comprising 458 patients. Hypertensive patients (HT group) received a diagnosis of hypertension before admission to our hospitals, according to Guideline Hypertension ESC-ESH 2018, and all patients were treated with common antihypertensive therapy (such as ACE.I, calcium antagonist, etc). Diabetic patients received a diagnosis of diabetes before admission to our hospitals, according to ADA 2021. Not-diabetic, not-hypertensive patients (not-DM-HT group) were patients consecutively enrolled in the study population. We acquired informed consent from all patients. Baseline characteristics are shown in Table 1. We now report the definition of ischemic heart disease, such as that described by the "Fourth Universal Definition of Myocardial Infarction" [10]: the lung disease is defined as reported by the 2002 American Thoracic Society and European Respiratory Society consensus statement [11], while the definition and classification of chronic kidney disease (CKD) have evolved over time, and current international guidelines define this condition as decreased kidney function shown by glomerular filtration rate (GFR) of less than $60 \mathrm{~mL} / \mathrm{min}$ per $1.73 \mathrm{~m}^{2}$ [12]. The definition of ischemic ictus is reported by [13].

Table 1. Characteristics baseline in DM-HT COVID-19 patients by gender differences. SBP (systolic blood pressure); DBP (diastolic blood pressure); DM (diabetes mellitus); CKD (chronic kidney disease); ICM (body mass index).

\begin{tabular}{cccc}
\hline & Female (n. 270) & Male (n. 286) & $p$ Value \\
\hline Age (mean) & $76.0(56.0-86.0)$ & $63.0(51.5-70.0)$ & $<0.0001$ \\
\hline Ischemic heart disease & $128(47.5 \%)$ & $42(14.8 \%)$ & $<0.0001$ \\
\hline Lung Disease & $93(34.8 \%)$ & $53(18.5 \%)$ & $<0.0001$ \\
\hline CKD & $0(0.01 \%)$ & $32(11.1 \%)$ & $<0.0001$ \\
\hline Prior Ischemic ictus & $121(44.9 \%)$ & $63(22.2 \%)$ & $<0.0001$ \\
\hline Stay hospital (days) & $17.0(9.0,23.0)$ & $22.0(16.0,33.0)$ & $<0.0001$ \\
\hline SBP $(\mathrm{mmHg})$ & $135(130-145)$ & $130(125-135)$ & $<0.0001$ \\
\hline DBP $(\mathrm{mmHg})$ & $78(74-88)$ & $72(70-84)$ & $<0.0001$ \\
\hline Basal glicemia & $135(140-165)$ & $130(135-160)$ & $<0.0001$ \\
\hline ICM $\left(\mathrm{kg} / \mathrm{m}^{2}\right)$ & $25(24.5-25.5)$ & $26(25.5-26.5)$ & 0.024 \\
\hline Smoking status $(\%)$ & $40(15)$ & $45(16)$ & $<0.0001$ \\
\hline
\end{tabular}

The clinical outcomes (i.e., discharges, mortality, length of stay, CT and Rx report, and therapy, admission on the intensive care) were monitored up to June 30, 2020. During hospitalization, we extracted, from electronic medical records, data on the use of drugs, demographic data, medical history, exposure history, comorbidities, symptoms, signs, 
laboratory findings, and treatment measures (i.e., antiviral therapy, LMWH therapy, corticosteroid therapy). The status of disease followed the guideline of SARS-CoV-2, reported as follows [5]:

- Mild type (with slight clinical symptoms but no imaging findings of pneumonia);

- Common type (with fever, respiratory tract, and imaging findings of pneumonia);

- Severe type (with any of the following conditions):

a. Respiratory distress with respiratory frequency $>30$ times/min;

b. Finger oxygen saturation at rest $93 \% \mathrm{AA}$; or

c. Oxygenation index $\left(\mathrm{PaO}_{2} / \mathrm{FiO}_{2}\right)<300 \mathrm{mmHg}$;

- Critical type (with any of the following conditions):

c. Respiratory failure that requires mechanical ventilation;

d. Shock and other organ failures that require intensive care unit.

Laboratory parameters, including complete blood count, hs-CRP (high-sensitivity Creactive protein), arterial blood gas analysis (ABG), myocardial injury markers, coagulation profile, serum biochemical tests (including renal and liver function, lactate dehydrogenase), PCT (procalcitonin), and BNP (b-type natriuretic peptide), were measured according to the manufacturer's instructions. Blood tests are repeated during hospitalization at admission, after $48 \mathrm{~h}$, and at discharge.

\section{Statistical Analysis}

Statistical significance $\alpha$ was fixed to 0.05 . Numerical variables were described as mean (SD) and compared through unpaired t-test. We used the unpaired student's $t$-test.

\section{Results}

The clinical characteristics of our population, by gender differences, are described in Table 1. In female DM-HT COVID-19 patients, compared to males, we observed a higher frequency of ischemic heart diseases, which aligns with another study [14] (47.5\% versus $14.8 \%$, respectively, $p: 0.001$ ). Additionally, we report a higher prevalence of lung diseases in DM-HT COVID-19 patients, compared to males ( $34.8 \%$ versus $18.5 \%$, respectively, $p$ : 0.001 ) and prior ischemic ictus ( $44.9 \%$ versus $22.2 \%$, respectively, $p: 0.001)$. Conversely, in male DM-HT COVID-19 patients, compared to females, we observed a higher proportion of renal diseases $(0.1 \%$ versus $11.1 \%$, respectively, $p: 0.001)$ (Figure 1 ).

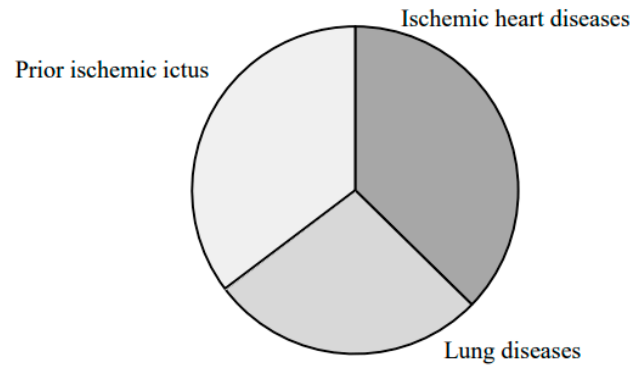

Female

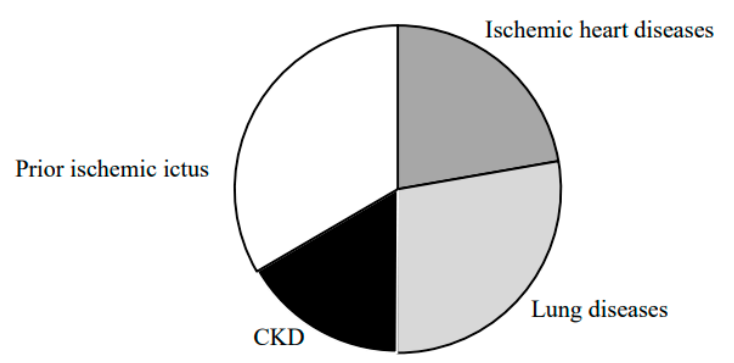

Male

Figure 1. Comorbidity by gender differences.

In relation to symptoms, we reported that fever is a common symptom in female patients $(85.2 \%$ vs. $42 \%, p<0.0001$, respectively) compared to male patients. Of note, that the hospital stay was higher in the male compared to the female group (22 days vs. 17 days; $p<0.0001$ ). In relation to epidemiological link, we observed higher proportion on community infection in male subjects, compared to females $(66.7 \%$ vs. $32.5 \%, p<0.0001)$, and a higher proportion of RSA infection in male $(40.7 \%$ vs. $7.4 \%, p<0.0001)$ (Figure 2$)$. We documented differences in relation to computerized tomography (CT) report by gender differences. In male subjects, compared to females, a higher proportion of atypical CT was 
reported ( $100 \%$ vs. $88.9 \%$, respectively, $p<0.0001)$. In Table 2 , we report the characteristics baseline in two groups (DM-HT and non-DM non -HT) COVID-19 patients.

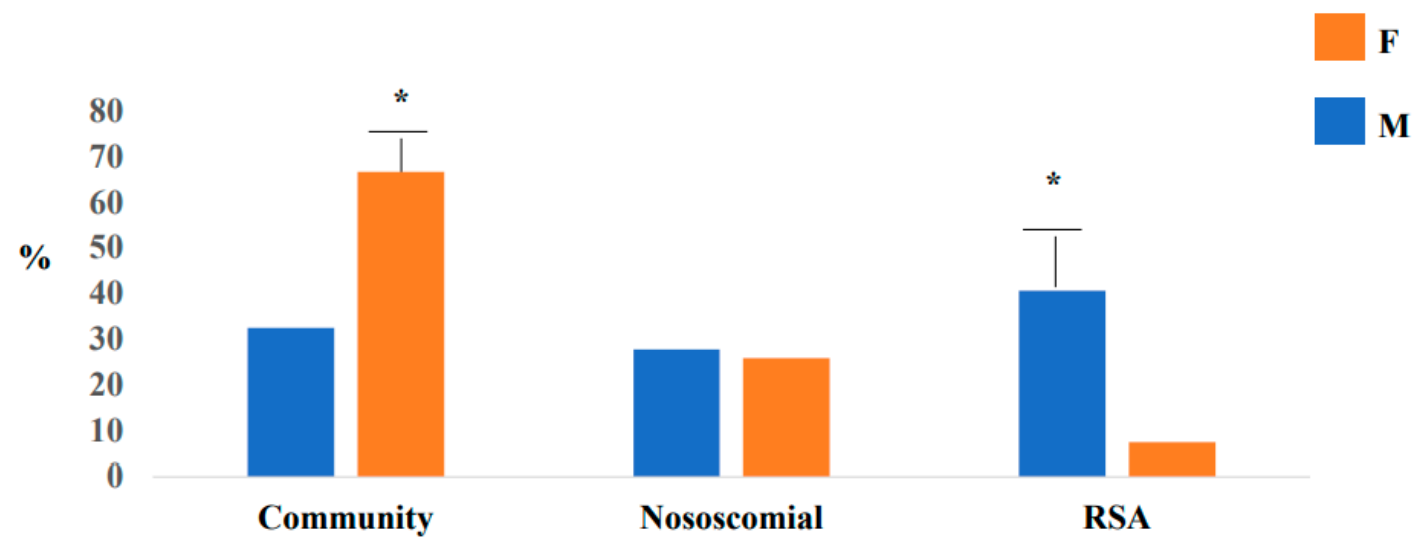

Figure 2. Epidemiological link by gender differences, ${ }^{*} p<0.001$. RSA (Residence assistance for elderly).

Table 2. Characteristics baseline in two groups (DM-HT and non-DM non -HT) of COVID-19 patients. SBP (systolic blood pressure); DBP (diastolic blood pressure); ICM (body mass index).

\begin{tabular}{cccc}
\hline & DM-HT Group (n. 556) & Non-DM Non-HT Group (n. 458) & $p$ Value \\
\hline Age $($ mean) & $76.0(56.0-86.0)$ & $67(51.0-83.0)$ & $<0.0001$ \\
\hline SBP $(\mathrm{mmHg})$ & $140(130-145)$ & $110(105-115)$ & $<0.0001$ \\
\hline DBP $(\mathrm{mmHg})$ & $90(85-100)$ & $77(70-84)$ & $<0.0001$ \\
\hline Basal glicemia & $137(140-165)$ & $110(105-115)$ & $<0.0001$ \\
\hline ICM $\left(\mathrm{kg} / \mathrm{m}^{2}\right)$ & $27(26.5-27.5)$ & $26.0(25.5-27.5)$ & 0.024 \\
\hline Smoking status $(\%)$ & $100(18)$ & $71(16)$ & 0.0039 \\
\hline
\end{tabular}

\section{Outcomes}

Outcomes by gender differences in DM-HT groups, were reported in Table 3 and are described here. In particular, in females, we report that $18.3 \%$ were of critical, $21.5 \%$ were severe, and $62 \%$ were mild. However, in our study, we described that $76.5 \%$ of females, compared to $3.4 \%$ of males, were discharged $(p<0.0001)$; $66.9 \%$ of males, compared to $12.8 \%$ of females, were admitted into the intensive care unit $(p<0.0001)$, as reported in Figure 3. However, males have a higher death rate $(17.3 \%$ vs. $10.7 \%, p<0.0001)$. In male subjects, we observed a higher proportion on the $\mathrm{O}_{2}$ therapy $(51.8 \%$ vs. $29.1 \%$, $p<0.0001$, respectively), and high-flow oxygen therapy with nasal cannula ( $100.0 \%$ vs. (93.7\%, $p<0.0001$, respectively) compared to female subjects. In relation to pharmacological therapy, we report a higher proportion on hydroxychloroquine in male subjects $(96.3 \%$ vs. $44.9 \%, p<0.0001)$ compared to female subjects. However, we observed a higher proportion of the Darunavir/ritonavir ( $7.4 \%$ vs. $0.0 \%, p<0.0001$, respectively) and on LMWH therapy $(70.4 \%$ vs. $30.5 \%, p<0.0001)$ in male subjects compared to female subjects. 


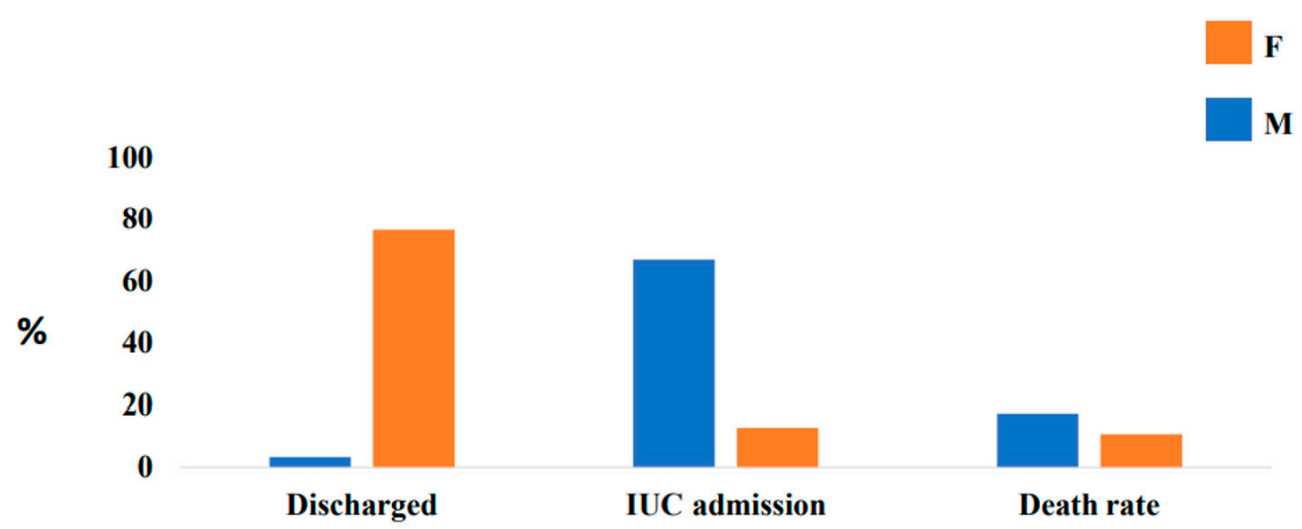

Figure 3. OUTCOME by gender differences.

Table 3. Gender differences in DM-HT groups. ICU (intensive care unit), CT (computerized tomography), high-flow nasal cannula (HFNC).

\begin{tabular}{|c|c|c|c|}
\hline & Male (n. 286) & Female (n. 270) & $p$ Value \\
\hline \multicolumn{4}{|l|}{ Epidemiological Link } \\
\hline Community & $180(66.7 \%)$ & $87(32.5 \%)$ & $<0.0001$ \\
\hline Nosocomial & $79(27.8 \%)$ & $70(25.9 \%)$ & 0.0016 \\
\hline RSA & $116(40.7 \%)$ & $20(7.4 \%)$ & $<0.0001$ \\
\hline \multicolumn{4}{|l|}{ Symptoms } \\
\hline Fever & $120(42.0 \%)$ & $230(85.2 \%)$ & $<0.0001$ \\
\hline Dyspnea & $148(51.9 \%)$ & $40(14.8 \%)$ & $<0.0001$ \\
\hline \multicolumn{4}{|l|}{ Rxlung } \\
\hline Atypical & $242(84.8 \%)$ & $69(25.7 \%)$ & $<0.0001$ \\
\hline Typical & $44(15.2 \%)$ & $200(74.3 \%)$ & $<0.0001$ \\
\hline \multicolumn{4}{|l|}{ CT lung } \\
\hline Atypical & $286(100.0 \%)$ & $240(88.9 \%)$ & $<0.0001$ \\
\hline Typical & $0(0.0 \%)$ & $30(11.1 \%)$ & $<0.0001$ \\
\hline PF ratio < $300(\%)$ & $58(20.3 \%)$ & $40(14.8 \%)$ & $<0.0001$ \\
\hline Discharge at home (\%) & $9(3.14 \%)$ & $206(76.5 \%)$ & $<0.0001$ \\
\hline ICU admission (\%) & $191(66.9 \%)$ & $34(12.8 \%)$ & $<0.0001$ \\
\hline Death rate $(\%)$ & $49(17.3 \%)$ & $28(10.7 \%)$ & $<0.0001$ \\
\hline $\mathrm{O}_{2}$ therapy & $140(51.8 \%)$ & $83(29.1 \%)$ & $<0.0001$ \\
\hline HFNC & $270(100.0 \%)$ & $267(93.7 \%)$ & $<0.0001$ \\
\hline Hydroxychloroquine & $128(44.9 \%)$ & $260(96.3 \%)$ & $<0.0001$ \\
\hline Darunavir/ritonavir & $21(7.4 \%)$ & $0(0.0 \%)$ & Ns \\
\hline LMWH therapy & $201(70.4 \%)$ & $82(30.5 \%)$ & $<0.0001$ \\
\hline
\end{tabular}

\section{Discussion}

It has been reported that pre-existing morbidities increase the severity of COVID-19 infection [15]. In particular, pre-existing cardiovascular (CV) risk factors, such as diabetes mellitus and cardiopathy, seem to be crucial predictors for COVID-19 severity. The fatality rate, in fact, was much higher in COVID-19 patients with comorbidities [16]. It is not known if hypertension could be a risk factor for susceptibility to contract COVID-19, but it is more prevalent in severe COVID-19 cases and in subjects with a negative outcome [8]. In this regard, different studies reported that hypertension and diabetes represent a crucial comorbidity in COVID-19 patients [17-22]. The relationship between diabetes, hypertension, and COVID-19 infection seems to be related to the role of ACE2 [22,23], which may act as a 
regulator of hypertension and also a receptor for SARS-CoV-2. The angiotensin-renin system, in fact, is dysregulated in subjects with hypertension and SARS-CoV-2 infection [24]. It has been described that hypertension is associated with higher plasma interleukin-6 concentration in COVID-19 patients [25,26]. Levels of IL-6 and other cytokines are not only prominent in patients with severe COVID-19 disease $[27,28]$ but could have profound CV consequences in patients with COVID-19 [29,30]. Mortality rate may increase by $10.5 \%$ for patients with $\mathrm{CV}$ risk factors, $7.3 \%$ for those with diabetes, and $6 \%$ for subjects with hypertension [31]. The histopathologic findings of diffuse alveolar damage (DAD) from COVID-19 appear to be indistinguishable from other causes of DAD. The acute/exudative phase of DAD is characterized by inflammatory cell-mediated alveolar damage with alveolar edema and/or hemorrhage, capillary congestion, and hyaline membranes with or without microvascular thrombi. The proliferative/organizing phase of DAD shows type II pneumocyte hyperplasia, reactive pneumocytes, alveolar wall thickening, and myofibroblast proliferation, whereas the chronic/fibrotic phase shows honeycomb lung with collagenous fibrosis of alveolar spaces and an interstitium with thickening of the alveolar wall along with squamous metaplasia of alveoli.

We designed this retrospective study to assess the gender differences in diabetichypertensive SARS-CoV-2 inpatients. In our population, we found in female DM-HT COVID-19 patients, compared to males, a higher proportion of ischemic heart diseases, lung diseases, and prior ischemic ictus. Conversely, in male DM-HT COVID-19 patients, compared to females, we observed a higher proportion of renal diseases. According to another study [29], male DM-HT COVID-19 patients had a higher hospital stay (22 days vs. 17 days; $p<0.001)$, a higher proportion of admission in intensive care units (ICUs) $(66.9 \%$ vs. $12.8 \%, p<0.001)$, and a higher death rate $(17.2 \%$ vs. $10.7 \%, p<0.001)$. Different studies reported that males seem to be more susceptible to COVID-19-related complications, and they represent between $50 \%$ and $82 \%$ of the hospitalized patients $[9,22]$. It is likely that our male patients were admitted more into ICUs because they are characterized by a higher proportion of atypical computerized tomography (CT), by higher proportion on the $\mathrm{O}_{2}$ therapy, and by high-flow oxygen therapy with nasal cannula. However, male subjects are characterized by a delay in access to care and they are admitted into hospitals in the advanced stages of the disease.

However, in relation to the epidemiological link, we observed, for the first time, a higher proportion of community infection in male subjects, compared to females, a higher proportion of RSA infection in smales. We report, for the first time, that male DM-HT subjects have a higher proportion of hydroxychloroquine and antiviral drugs compared to female subjects. However, our males needed aggressive therapies, probably in relation to their severity of disease and delay in access to care. These differences may depend on different crucial factors. In particular, we report that our male DM-HT subjects are characterized by a higher proportion of atypical tomography computerized (CT). These data could be related to probable delay in access to care for male patients; i.e., only in the advanced stages of the disease. In addition, even the atypical CT report, in males, could lead to the administration of a more aggressive therapy. Therefore, gender differences should be one of the criteria to select the appropriate therapies for the appropriate patients.

\section{Conclusions and Study Limitations}

The mechanisms by which hypertension and diabetes induce poor clinical outcomes in male COVID-19 patients remain obscure. We reported that DM-HT can be an important risk factor for progression and unfavorable outcomes in COVID-19 patients. The novelty of our paper is that we reported preliminary gender differences in relation to epidemiological link, CT report, and outcome (such as death rate, admission on the ICU, hospital stay). Of course, our study has several limitations. First, interpretation of our findings might be limited by the sample size and the retrospective observational nature of the study. Second, males received hydroxychloroquine more frequently, and it could be responsible for a worse clinical situation. Third, the influence of diabetes and hypertension on severity and 
outcome in COVID-19 patients, by gender differences, is not clear because of the large gap in the evidence. Finally, the follow-up period of this study is short to assess the prognosis of COVID-19. Large studies with comprehensive analysis of all risk factors and longer follow up are necessary to answer all questions that have been raised.

Author Contributions: T.C., F.C. and V.D.P. Conceptualization; T.C., F.C. and V.D.P.; Methodology, G.C. and T.C.; Software, T.C.; Validation G.C., M.D. and M.G., Formal analysis, T.C.; Investigation, T.C.; Resources, F.C.; Data curation, T.C.; Writing—original draft preparation, T.C.; Writing—review and editing, T.C.; Visualization, T.C. and M.D. Supervision, M.G.; Project administration, M.G.; Funding acquisition, not applicable. All authors have read and agreed to the published version of the manuscript.

Funding: This research received no external funding.

Institutional Review Board Statement: Not applicable.

Informed Consent Statement: Not applicable.

Data Availability Statement: Not applicable.

Acknowledgments: We thank Domenico Caruso, Internal Medicine Department, Hospital of Cardarelli Naples; Ada Maffettone, Internal Medicine Department, A.O. Colli, Naples. The authors thank all FADOI Group Campania.

Conflicts of Interest: The authors declare no conflict of interest.

\section{References}

1. OMS. Health Emergency Dashboard. 2021. Available online: https://www.who.int/emergencies/diseases/novel-coronavirus2019 (accessed on 19 August 2021).

2. Fang, L.; Karakiulakis, G.; Roth, M. Are patients with hypertension and diabetes mellitus at increased risk for Covid-19 infection? Lancet Respir. Med. 2020. [CrossRef]

3. Zhang, J.J.; Dong, X.; Cao, Y.Y.; Yuan, Y.D.; Yang, Y.B.; Yan, Y.Q.; Akdis, C.A.; Gao, Y.D. Clinical characteristics of 140 patients infected with SARS- CoV-2 in Wuhan, China. Allergy 2020, 1-12. [CrossRef] [PubMed]

4. Li, B.; Yang, J.; Zhao, F.; Zhi, L.; Wang, X.; Liu, L.; Zhao, Y. Prevalence and impact of cardiovascular metabolic diseases on COVID-19 in China. Clin. Res. Cardiol. 2020, 109, 531-538. [CrossRef]

5. Guan, W.J.; Ni, Z.Y.; Hu, Y.; Liang, W.-H.; Ou, C.-Q.; He, J.-X.; Liu, L.; Shan, H.; Lei, C.-L.; Hui, D.S.C.; et al. Clinical Characteristics of Coronavirus Disease 2019 in China. N. Engl. J. Med. 2020, 382, 1708-1720. [CrossRef] [PubMed]

6. Sun, M.L.; Yang, J.M.; Sun, Y.P.; Su, G.H. Inhibitors of RAS might be a good choice for the therapy of COVID-19 pneumonia. Zhonghua Jie He He Hu Xi Za Zhi 2020, 43, 219-222.

7. Levy, B.I.; Heusch, G.; Camici, P.G. The many faces of myocardial ischaemia and angina. Cardiovasc 2019, 115, 1460-1470. [CrossRef]

8. Onder, G.; Rezza, G.; Brusaferro, S. Case-fatality rate and characteristics of patients dying in relation to COVID-19 in Italy. JAMA 2020, 323, 1775-1776. [CrossRef] [PubMed]

9. Huang, F.; Wei, C.; Zhang, Y. A meta-analysis of sex differences in severity and mortality among patients with COVID-19. Ann. Med. 2021, in press.

10. Thygesen, K.; Alpert, J.S.; Jaffe, A.S.; Chaitman, B.R.; Bax, J.J.; Morrow, D.A.; White, H.D. The Joint European Society of Cardiology/American College of Cardiology/American Heart Association/World Heart Federation Task Force for the Universal Definition of Myocardial Infarction: The Executive Group on behalf of the Joint European Society of Cardiology (ESC)/American College of Cardiology (ACC)/American Heart Association (AHA)/World Heart Federation (WHF) Task Force for the Universal Definition of Myocardial Infarction. Fourth Universal Definition of Myocardial Infarction. Circulation 2018, 138, e618-e651. [CrossRef]

11. Travis, W.D.; Costabel, U.; Hansell, D.M.; King, T.E., Jr.; Lynch, D.A.; Nicholson, A.G.; Ryerson, C.J.; Ryu, J.H.; Selman, M.; Wells, A.U.; et al. An official American Thoracic Society/European Respiratory Society statement: Update of the international multidisciplinary classification of the idiopathic interstitial pneumonias. ATS/ERS Committee on Idiopathic Interstitial Pneumonias. Am. J. Respir. Crit. Care Med. 2013, 188, 733-748. [CrossRef] [PubMed]

12. Webster, A.C.; Nagler, E.V.; Morton, R.L. Philip Masson Chronic Kidney Disease. Lancet 2017, 389, 1238-1252. [CrossRef]

13. de Leciñana, M.A.; Egido, J.A.; Casado, I.; Ribó, M.; Dávalos, A.; Masjuan, J.; Vivancos, J. Spanish Neurological Society. Guidelines for the treatment of acute ischaemic stroke. Neurologia 2014, 29, 102-122. [CrossRef]

14. Pasupathy, S.; Air, T.; Dreyer, R.P.; Tavella, R.; Beltrame, J.F. Systematic review of patients presenting with suspected myocardial infarction and nonobstructive coronary arteries. Circulation 2015, 131, 861-870. [CrossRef] [PubMed] 
15. Swati, S.; Mary, F.; Carol, F.; Allecia, M.W.; Albino, E.; Ilaria, G.; Elisabet, P.; Clare, B.; Fadi, S.; Siraj, M.E.J.; et al. Postmortem Findings Associated with SARS-CoV-2: Systematic Review and Meta-analysis. Am. J. Surg. Pathol. 2021, 45, 587-603. [CrossRef]

16. Marin, B.G.; Aghagoli, G.; Lavine, K.; Yang, L. Predictors of COVID-19 severity: A literature review. Med. Virol. 2021, 31, 1-10. [CrossRef]

17. Guzik, T.J.; Mohiddin, S.A.; Dimarco, A.; Patel, V.; Savvatis, K.; Marelli-Berg, F.M.; Madhur, M.S.; Tomaszewski, M.; Maffia, P.; D'Acquisto, F. COVID-19 and the cardiovascular system: Implications for risk assessment, diagnosis, and treatment options. Cardiovasc. Res. 2020, 116, 1666-1668. [CrossRef]

18. National Health Commission of the People's Republic of China. Chinese Clinical Guidance for COVID-19 Pneumonia Diagnosis and Treatment (7th Edition). 2020. Available online: http:// kjfy.meetingchina.org/msite/news/show / cn/3337.html (accessed on 19 August 2021).

19. Lauer, S.A.; Grantz, K.H.; Bi, Q.; Jones, F.K.; Zheng, Q.; Meredith, H.R.; Azman, A.S.; Reich, N.G.; Lessler, J. The incubation period of coronavirus disease 2019 (COVID-19) from publicly reported confirmed cases: Estimation and application. Ann. Intern Med. 2020. [CrossRef]

20. Zhou, C.; Gao, C.; Xie, Y.; Xu, M. COVID-19 with spontaneous pneumomediastinum. Lancet Infect. Dis. 2020, 20, 510. [CrossRef]

21. Sun, R.; Liu, H.; Wang, X. Mediastinal emphysema, giant bulla, and pneumothorax developed during the course of COVID-19 pneumonia. Korean J. Radiol. 2020, 21, 544. [CrossRef] [PubMed]

22. Grasselli, G.; Zangrillo, A.; Zanella, A.; Antonelli, M.; Cabrini, L.; Castelli, A.; Cereda, D.; Coluccello, A.; Foti, G.; Fumagalli, R.; et al. Baseline Characteristics and Outcomes of 1591 Patients Infected With SARS-CoV-2 Admitted to ICUs of the Lombardy Region, Italy. JAMA 2020, 323, 1574-1581. [CrossRef]

23. Epidemiology Working Group for NCIP Epidemic Response. The epidemiological characteristics of an outbreak of 2019 novel coronavirus diseases (COVID-19) in China. Chin. J. Epidemiol. 2020, 41, 145-151.

24. Vaduganathan, M.; Vardeny, O.; Michel, T.; McMurray, J.J.V.; Pfeffer, M.A.; Solomon, S.D. Renin-angiotensin-aldosterone system inhibitors in patients with Covid-19. N. Engl. J. Med. 2020. [CrossRef]

25. Drummond, G.; Vinh, A.; Guzik, T.; Sobey, C.G. Immune mechanisms of hypertension. Nat. Rev. Immunol. 2019, 19, 517-532. [CrossRef] [PubMed]

26. Loperena, R.; Van Beusecum, J.P.; Itani, H.A.; Engel, N.; Laroumanie, F.; Xiao, L.; Elijovich, F.; Laffer, C.L.; Gnecco, J.S.; Noonan, J.; et al. Hypertension and increased endothelial mechanical stretch promote monocyte differentiation and activation: Roles of STAT3, interleukin 6 and hydrogen peroxide. Cardiovasc. Res. 2018, 114, 1547-1563. [CrossRef] [PubMed]

27. Wang, S.; Zhang, Q.; Wang, P.; Ye, H.; Jing, X.; Zhang, Z.; Zhu, S.; Luo, T.; Zheng, Z. Clinical features of hypertensive patients with COVID-19 compared with a normotensive group: Single-center experience in China. Open Med. 2021, 16, 367-374. [CrossRef]

28. Siedlinski, M.; Jozefczuk, E.; Xu, X.; Teumer, A.; Evangelou, E.; Schnabel, R.B.; Welsh, P.; Maffia, P.; Erdmann, J.; Tomaszewski, M.; et al. White blood cells and blood pressure: A Mendelian randomization study. Circulation 2020, 141, 1307-1317. [CrossRef]

29. Steven, S.; Dib, M.; Hausding, M.; Kashani, F.; Oelze, M.; Kroller-Schon, S.; Hanf, A.; Daub, S.; Roohani, S.; Gramlich, Y.; et al. CD40L controls obesity-associated vascular inflammation, oxidative stress, and endothelial dysfunction in high fat diet-treated and $\mathrm{db} / \mathrm{db}$ mice. Cardiovasc. Res. 2018, 114, 312-332. [CrossRef] [PubMed]

30. Ruan, S. Likelihood of survival of coronavirus disease 2019. Lancet Infect. Dis. 2020. [CrossRef]

31. Liu, Z.; Bing, X.; Zhi, Z. Novel Coronavirus Pneumonia Emergency Response Epidemiology Team. Epidemiol. Charact. Outbreak 2020, 41, 145-151. [CrossRef] 